\title{
AS PRÁTICAS PEDAGÓGICAS DOS PROFESSORES DA EDUCAÇÃO BÁSICA NA INTERAÇÃO COM OS LIVROS DIDÁTICOS DIGITAIS
}

\author{
Eliane Mimesse Prado ${ }^{1}$
}

\begin{abstract}
Resumo
Este estudo analisa a interação das práticas pedagógicas dos professores da Educação Básica com os livros didáticos digitais. 0 objetivo foi 0 de verificar quais os usos cotidianos dos livros didáticos digitais nas salas de aula. Efetuou-se uma pesquisa de campo, que, por sua vez, se concretizou a partir da distribuição de questionários a alguns professores que lecionam em escolas de grande porte na rede privada da cidade de Curitiba, Estado do Paraná. A fundamentação teórica desenvolveu-se a partir de Batista (2002) e Bittencourt (2008), que apresentam o contexto histórico dos livros escolares, Cassiano (2014), que analisa a expansão do mercado editorial dos livros didáticos, e Ribeiro (2011), que identifica as novas necessidades dos professores em adaptarem-se aos novos suportes de leitura. Conclui-se que 0 livro didático digital ainda não atingiu plenamente as práticas pedagógicas dos professores, apesar do foco deste estudo estar centrado nas grandes escolas privadas da cidade.
\end{abstract}

Palavras-chave: Práticas pedagógicas. Livros didáticos digitais. Educação básica.

\section{PEDAGOGICAL PRACTICES USED BY ELEMENTARY SCHOOL TEACHERS REGARDING DIGITAL TEXTBOOKS}

\begin{abstract}
This paper analyses the interaction of pedagogical practices used by elementary school teachers and digital textbooks. The objective was to verify how these digital textbooks were used in classroom on a daily basis. There has been a field research by handing out some questionnaires to some teachers who work in large private schools in Curitiba. The theoretical basis was developed from Batista (2002) and Bittencourt (2008) who describe the historical context of textbooks, Cassiano (2014) who analyses the spreading of textbooks publishing market and Ribeiro (2011) who identifies the contemporary needs of teachers regarding this new reading media. It was concluded that the digital textbook has not fully reached the teachers pedagogical practices yet, even though the core of this paper being focused on large private schools of Curitiba.
\end{abstract}

Keywords: Pedagogical practices. Digital textbooks. Elementary school.

1 Doutora em Educação pela PUC/SP. Pós-doutora em Educação pela FE/USP, Pesquisadora do PPG em Educação da UCS. emimesse@bol.com.br 
Os livros escolares ou didáticos são utilizados há tempos nas salas de aula. Esses livros sempre tiveram o objetivo de contribuir com a metodologia de ensino dos professores, reforçando a aprendizagem em sala de aula e fora dela.

A criação dos livros digitais proporcionou aos leitores uma nova possibilidade de acesso à leitura. Os suportes necessários à leitura de livros neste formato estão cada dia mais difundidos e acessíveis ao consumidor-leitor. Sendo assim, como consequência dessa ação, os livros didáticos passaram paulatinamente a assumir o formato digital. A introdução dos livros didáticos digitais nas salas de aula trouxe consigo novas necessidades de aprendizagem e domínio tecnológico aos professores e aos alunos, o que, por sua vez, acarretou outros fatores impeditivos ao seu pleno desenvolvimento. A introdução descomedida de suportes eletrônicos nas salas de aula - por parte dos alunos - gerou certa indisciplina, principalmente às disciplinas em que os professores ainda não sabiam como utilizar esses meios. Em decorrência de alguns casos de usos inadequados pelos alunos dos suportes para leitura dos livros, constatou-se certa opressão com relação à utilização dos suportes e aos modos de emprego destes pelos alunos quando se encontraram em sala de aula.

No texto que se segue serão abordadas questões relativas às origens dos livros escolares impressos, como ocorreram seus usos e como esse processo aconteceu. Desde as ideias iniciais sobre os livros escolares na França e as influências destes nas salas de aula brasileiras, nos anos finais do século $19 \mathrm{e}$ no decorrer dos séculos 20 e 21 ? Quais as modalidades de escolas primárias brasileiras que foram as primeiras a adotar manuais ou livros didáticos em seu cotidiano? Como esses manuais eram distribuídos e quem eram seus autores? Nesse ínterim, convém relacionar as comissões e programas criados pelo governo para a organização da distribuição de livros didáticos nas escolas públicas no decorrer do século 20. Quais as influências na redação dos conteúdos advindas dos parâmetros curriculares nacionais e a necessidade de criação de um programa nacional do livro didático? Ainda, como os professores selecionam seus livros e quais as alternativas destas escolhas? 
No Estado do Paraná os próprios professores escreveram seus livros para o Ensino Médio, em um projeto direcionado pela Secretaria da Educação. Como as editoras se uniram e formaram grandes grupos para a publicação e distribuição de livros didáticos? Por fim, como os livros didáticos digitais reverteram grande parte deste histórico e banalizaram os problemas enfrentados com a produção de textos com equívocos ou com a distribuição dos volumes?

Foram elaborados questionários para verificar qual o nível de inclusão dos livros didáticos digitais nas salas de aula de algumas escolas privadas de grande porte, localizadas na cidade de Curitiba, Estado do Paraná. Os professores entrevistados, em sua maioria, por trabalharem em escolas privadas frequentadas por alunos das classes mais abastadas, têm acesso a materiais inovadores em seu cotidiano. Apenas uma pequena minoria, no entanto, faz uso nas salas de aula dos livros digitais. Esses profissionais consideram relevante a inserção desta tecnologia nas escolas para facilitar o ensino e a aprendizagem dos conteúdos, mas, ao mesmo tempo, não descartam a manutenção dos livros impressos.

A temática apresentada neste artigo ainda está em processo de expansão. $\mathrm{Na}$ verdade este será um experimento inicial acerca da problemática que envolve o uso dos livros didáticos digitais na prática pedagógica dos professores.

\section{Os Livros Escolares nas Salas de Aulas}

O livro escolar, por ser uma modalidade diferente, foi descrito por Batista (2002, p. 529) como um objeto variável e instável. Nesse sentido "é efêmero, se desatualiza com muita velocidade. Raramente é relido". Os livros escolares surgiram com a necessidade de contribuir com o trabalho do professor.

Na França do século 19 tem-se notícias do uso de livros nesse molde nos anos iniciais de escolarização. Os manuais escolares tinham a função de reforçar os conteúdos ensinados aos alunos. No Brasil, as influências francesas eram grandes, como citado por Bittencourt (2008).Com a proclamação da República, novos decretos de ensino foram criados para reorganizar a escolarização elementar de uma população em franco crescimento. 
Esse era o período em que o Brasil recebeu muitos imigrantes, das mais variadas etnias, e, nesse sentido, coexistia a necessidade de se alfabetizar o estrangeiro. Os livros escolares, principalmente os de leitura, poderiam contribuir indiretamente com a aproximação da população estrangeira ao idioma do país. Existiam decretos que previam a distribuição dos livros para as escolas de ensino primário públicas estaduais, como já ocorria nas escolas francesas. O papel de um livro didático, conforme descrito por Bittencourt (2008, p. 63), era o de ser "[...] um poderoso instrumento para fixar e assegurar determinada postura educacional. [...] deveria se encarregar de uniformizar o saber escolar". Sendo assim, era necessária uma certa inquietação por parte do governo com a produção e a distribuição dos livros escolares nos anos iniciais do período republicano, por volta do final do século 19 e anos iniciais do século 20.

A distribuição dos livros escolares passou a ser mais eficiente à medida que foram criados os Grupos Escolares. Nessa modalidade de escola os alunos eram separados por sexo, idade e ano de ensino. Os conteúdos passaram a ser divididos de acordo com a segmentação escolar. As crianças, alunas dos Grupos, tinham um ensino mais conciso, mais metódico e ainda recebiam os livros de texto para estudarem para as aulas.

No Brasil, nos anos finais do século 19 e iniciais do 20, existiam escolas primárias de várias modalidades. O que predominava no país eram as escolas isoladas, que poderiam ser masculinas, femininas ou mistas. Essa última, chamada de mista, foi também conhecida, em algumas localidades do Brasil, como escola promíscua, exatamente por ter meninos e meninas na mesma sala de aula. Existiam também as escolas reunidas, que, como expressa sua denominação, era uma escola que reunia em um mesmo local algumas escolas isoladas. Sendo assim, os livros eram distribuídos principalmente para os Grupos Escolares por sua organização escolar para, desta forma, proporcionarem uma melhor condição na aprendizagem das crianças, e por estarem, normalmente, localizados nas áreas centrais das cidades. Sendo assim, as escolas isoladas e reunidas nem sempre recebiam os livros que eram selecionados e depois enviados pelo governo. A prioridade era dos Grupos Escolares. 
A distribuição dos livros escolares era falha nas escolas públicas. Os professores das escolas isoladas redigiam relatórios individuais semestrais, que eram enviados ao diretor da Instrução Pública. Nesses relatórios os professores descreviam suas aulas, a participação dos alunos e solicitavam materiais para o ensino. Os livros normalmente eram requeridos nesses relatórios com títulos e nomes dos autores, conforme descrito por Mimesse (2010).

A elaboração de manuais para o ensino perpassou todos os anos de escolarização. Dessa forma, muitos dos livros escolares eram trazidos de outros países para uso dos alunos mais velhos, que tinham leitura em outro idioma. No então denominado ensino secundário - que correspondia aos anos posteriores ao ensino primário -, os alunos tinham aulas de várias matérias e também de línguas estrangeiras. Nessa época incluía-se o ensino de até três idiomas diferentes.

No caso dos alunos mais novos, os seus livros eram, muitas vezes, traduzidos por professores que lecionavam nas Escolas Normais. Os professores que traduziam livros para a Língua Portuguesa passaram a ter a possibilidade de se tornarem autores de livros escolares. Um exemplo desta ação foi a tradução do livro Coração, por João Ribeiro, do original em italiano chamado Cuore, no ano de 1891. Este livro era adotado para os terceiros anos dos Grupos Escolares e descrevia as memórias de um menino, escritas em forma de diário, sobre as situações que viveu durante suas aulas. Cada capítulo relatava o acontecimento de um mês do ano. A ação ocorria em uma sala de terceiro ano do curso primário. Com o passar dos tempos vários professores do quadro das Escolas Normais escreveram livros de leitura, cartilhas, livros de aritmética, de ciências, entre outros, todos voltados para os anos iniciais do ensino.

Diante desse quadro, vê-se que não existiam muitas possibilidades de escolha de um livro escolar. Muitos autores desses livros escreveram sobre o mesmo assunto durante anos, e não surgiram outros livros que abordassem os conteúdos sob outros pontos de vista. Identificaram-se livros que eram recomendados aos professores durante anos consecutivos, que poderiam ser escolhidos pelos professores do Estado de São Paulo nos três primeiros anos do ensino primário. 
Conforme Höfling (2000), no ano de 1938 foi instituída a Comissão Nacional do Livro Didático. Essa Comissão criou condições para produção, importação e utilização do livro didático no país. Em 1945 as funções dessa Comissão Nacional foram revisadas, e passou a fazer parte da esfera federal. Com o passar do tempo, alguns Estados instituíram suas próprias comissões. Em 1967 foi criada a Fundação Nacional de Material Escolar, que assumiu as funções da antiga Campanha Nacional de Material de Ensino. A Fundação Nacional de Material Escolar tinha a finalidade de produzir e distribuir material didático às escolas. Em 1970 foi celebrado um acordo de cooperação da Fundação Nacional de Material Escolar com as editoras nacionais.

Em 1972 foi criado o Instituto Nacional do Livro, assumindo as tarefas da extinta Comissão do Livro Técnico e Didático, que teve existência de apenas seis anos. A função do Instituto Nacional do Livro era a de "promover e agilizar o programa de coedição de obras didáticas”, como escreveu Höfling (2000, p. 163).

O Instituto Nacional do Livro criou um programa para a coedição - o Programa do Livro Didático. Esse programa foi dividido em outros quatro programas para o Fundamental, o Médio, o Superior e o Supletivo. Em 1983 as atividades da Fundação Nacional de Material Escolar e do Programa do Livro Didático foram transferidas para a Fundação de Assistência ao Estudante. No ano de 1984 findou a coedição e o Ministério da Educação passou a comprar os livros didáticos diretamente das editoras. Segue um Quadro com a síntese das alterações nos órgãos governamentais.

Quadro 1 - Síntese das mudanças nos programas sobre livros didáticos

\begin{tabular}{|l|l|}
\hline $\begin{array}{c}\text { Ano de } \\
\text { criação }\end{array}$ & Nomes dos órgãos públicos \\
\hline 1938 & Comissão Nacional do Livro Didático (CNLD) \\
\hline 1945 & Comissão Nacional do Livro Didático, foi revisada \\
\hline 1967 & Fundação Nacional do Material Escolar (Fename) \\
\hline 1970 & Fundação Nacional do Material Escolar (Fename), uniu-se às editoras nacionais \\
\hline 1972 & Instituto Nacional do Livro (INL), criou o Programa do Livro Didático (Plid) \\
\hline 1983 & $\begin{array}{l}\text { Fundação Nacional do Material Escolar (Fename), uniu-se ao Programa do Livro } \\
\text { Didático (PLID) e gerou a Fundação de Assistência ao Estudante (FAE) }\end{array}$ \\
\hline 1984 & Ministério da Educação (MEC), passou a comprar os livros didáticos das editoras \\
\hline
\end{tabular}

Fonte: Höfling, 2000. 


\section{A Disseminação do Livro Didático e os Programas Oficiais}

Atualmente os livros seguem um programa do governo para sua divulgação e futura escolha pelos professores. A distribuição gratuita em grande escala de livros didáticos pelo governo teve início no ano de 1966, quando se criou a Comissão do Livro Técnico e do Livro Didático (Colted), com a função de distribuí-los em um curto período de tempo. Já nessa época nem todas as escolas recebiam os livros no prazo, isto é, antes do início do ano letivo. Conforme Prado (2014), essa Comissão foi criada para tentar sanar essa dificuldade. Além disso, nem todas as séries eram contempladas com a distribuição gratuita, pois a prioridade do governo recaía sempre sobre as primeiras séries do Ensino Básico.

A produção de materiais escolares atualmente no Brasil é ampla. Temos de levar em conta que as editoras produzem livros didáticos, paradidáticos e apostilas de ensino para as mais diferentes faixas etárias. $\mathrm{O}$ formato desses livros é sempre similar, independentemente de seu objetivo. Os materiais didáticos voltados para o ensino seguem um padrão.Eles devem conter letras com fontes e cores diferentes, imagens, quadros ou tabelas que ilustrem as passagens, e, em muitos casos, atividades e exercícios que contribuam para a fixação dos conteúdos descritos, e ainda um número máximo de páginas.

O único modelo que não segue essas especificações é o livro paradidático. Esse livro é temático, aprofunda a discussão de algum assunto em especial; normalmente traz imagens para contribuir com a compreensão dos conteúdos, além de fatos do cotidiano pouco conhecidos pelos alunos leitores.

Um outro formato de livro é digital. Esses livros comumente são utilizados por escolas privadas, em acordo com pais e empresas. Os alunos recebem os livros escolares em um equipamento eletrônico específico, ou, como ocorre em algumas situações, os livros são baixados diretamente da página da editora, no formato PDF, nos suportes de propriedade de cada aluno.

Foram criados programas de governo visando à melhoria na aprendizagem e, de certa forma, contribuíram para a redação dos conteúdos nos livros didáticos. Um desses programas - os Parâmetros Curriculares Nacionais - ela- 
borados por equipes, divulgaram as versões preliminares no ano de 1995. Cada volume era voltado para uma área da educação Fundamental. Algumas cópias foram distribuídas aos especialistas de cada área para análise, e, desta forma, reelaboradas as segundas versões quando necessárias e, assim, encaminhadas ao Conselho Federal de Educação. Os Parâmetros Curriculares Nacionais foram escritos entre os anos de 1995 e 1998. À medida que eram finalizados passaram a ser publicados. Algumas equipes tiveram um tempo maior para sua elaboração em razão de questões ideológicas, como o caso da disciplina de História.

Os Parâmetros Curriculares Nacionais foram criados para se tornarem um referencial para a educação no Ensino Fundamental. Teriam a função de manterem a coerência nos conteúdos a serem ensinados, nas mais variadas regiões do país. Como era apenas um parâmetro, sua proposta poderia ser alterada, e era flexível de acordo com as regiões geográficas e seus respectivos interesses.

No ano de 1999 foram criados os Parâmetros Curriculares Nacionais do Ensino Médio.Em 2002, para complementar os conteúdos dos parâmetros do Ensino Médio, publicaram-se os Parâmetros Curriculares Nacionais+. Esses últimos atribuíam maior importância à interdisciplinaridade e à contextualização dos conteúdos nas mais diversas áreas. Deste modo, a grande maioria dos livros didáticos existentes no mercado ainda hoje são pautados pelos conteúdos expressos nos Parâmetros Curriculares Nacionais. Os que não seguem essas diretrizes acabam por serem reprovados na análise efetuada pelo próprio governo e que, posteriormente, são listados no Guia Nacional dos Livros Didáticos.

O Programa Nacional do Livro Didático é um programa criado oficialmente pelo governo federal no ano de 1996. Esse programa teve como finalidade selecionar, expor e indicar os manuais didáticos, seguindo os aspectos negativos e positivos de cada obra, sendo regulamentado e dirigido pelos Parâmetros Curriculares Nacionais de cada área específica, caracterizando-os por meio de princípios científicos e conceituais.

Antes do Programa Nacional do Livro Didático existiram vários programas para o livro didático que visaram a reestruturar o sistema de distribuição do livro escolar para as oito séries do Ensino Fundamental, mas que atendia, a princípio, as quatro séries iniciais do Elementar. Segundo Cassiano (2014), a 
distribuição era falha e existiam outros entraves nesse processo, como o preenchimento equivocado dos formulários de solicitação de volumes pelos professores. No ano de 1994 o programa atingiu todas as oito séries do Ensino Fundamental. Somente em 1997, porém, foi criado o Fundo Nacional de Desenvolvimento para a Educação, órgão que regulamentava as ações do Programa Nacional e que se tornou responsável pela distribuição do livro didático.

Os problemas existentes com a distribuição dos livros foram paulatinamente sanados. Para tanto, foi necessário que os alunos fossem identificados por meio de suas matrículas, de tal modo a priorizar o envio de determinadas quantidades de volumes para as escolas, e, ainda, por designar a Empresa Brasileira de Correios e Telégrafos como responsável pela distribuição dentro dos prazos preestabelecidos como escreveu Cassiano (2014). Assim, a questão da dificuldade de acesso aos livros pelos alunos foi parcialmente resolvida ainda no final dos anos 90 .

O principal objetivo do Programa Nacional do Livro Didático é o de "subsidiar o trabalho pedagógico dos professores por meio da distribuição de coleções de livros didáticos aos alunos da educação básica” (Brasil, 2014). A partir dos volumes avaliados pelos pareceristas, o governo publica o Guia Nacional de Livros Didáticos, que é encaminhado às escolas.

Neste ponto, é necessário explicar quem são os pareceristas dos livros didáticos que participam da escrita dos Guias Nacionais de cada área. Desde o ano de 1996 os livros didáticos que pretendessem ser selecionados eram encaminhados para uma comissão no Ministério da Educação. Essa inovação na avaliação dos livros criou, como citou Munakata (2002, p. 593), "um novo grupo de leitores- o dos avaliadores -, reduzidíssimo em número, mas altamente poderoso, na medida em que é capaz de influir sobre a aquisição, pelo governo, de milhões de livros didáticos”. Esses pareceristas são, na maioria das vezes, professores vinculados a instituições públicas de ensino superior. Têm a função de analisar e classificar cada livro enviado para a seleção do Programa Nacional do Livro Didático, e que, se escolhidos, constarão do Guia Nacional. 
O Guia contém comentários e súmulas sobre cada um dos volumes que foram selecionados pelos pareceristas, e é considerado fundamental ao Programa Nacional do Livro Didático.

\section{Os Livros Didáticos nas Escolas}

Em pesquisa realizada com professores do Ensino Fundamental, verificou-se que as opções na escolha dos livros didáticos dependem principalmente do critério de cada profissional. Muitos professores escolhem livros de autores que já trabalharam em anos anteriores; em algumas situações as editoras são a prioridade, não os autores. Alguns primam pela escolha de livros com maior número de imagens, ilustrações e exercícios, de modo que não existe uma coesão na escolha dos volumes.

De acordo com Cassiano (2014), os livros didáticos possuem tanto uma dimensão econômica quanto político-ideológica. Esses livros são, antes de tudo, uma mercadoria, um produto do mundo da edição que obedece à evolução das técnicas de fabricação e comercialização pertencentes à lógica do mercado. Nessas condições, a sua dimensão econômica pode ser definida pelo fato de que responde por cerca da metade do mercado editorial brasileiro.

Os livros didáticos são materiais carregados de ideologias e pensamentos específicos, desde a sua escrita até a sua escolha. Isso ocorre em virtude da formação e ideologia do próprio autor, e também da formação e ideologia dos próprios pareceristas - que analisam os livros que devem compor o Guia Nacional dos Livros Didáticos, que são os que escolhem os livros didáticos a serem utilizados pela maioria das escolas públicas.

Os livros didáticos trazem um saber sistematizado sobre os mais variados temas e situações, podendo privilegiar alguns, ignorar e silenciar outros, como resultado dos processos de escolha e seleção pelos quais passaram os conteúdos e as formas de didatização e apresentação desses conteúdos que acabam, finalmente, por se expressarem no conjunto de manuais disponibilizados para a escolha dos professores. 
Para tentar oferecer novas possibilidades de escolhas de livros didáticos, alguns governos estaduais produziram seus próprios livros didáticos para serem distribuídos para as escolas públicas. São livros escritos por professores da rede pública, e contam com exemplares para cada disciplina que compõe os anos do Ensino Médio.

O Estado do Paraná efetivou a criação de um projeto denominado Folhas, e a consequente publicação de um Livro Didático Público. Esse projeto e essa publicação foram justificados pelo governo em razão da falta de flexibilidade do mercado editorial de livros didáticos, por esses não apresentarem possibilidades de se trabalhar com outros tipos de manuais didáticos. De acordo com Prado (2010), estes livros foram produzidos pelos próprios professores da rede pública e elaborados, a princípio, apenas para as três últimas séries do Ensino Médio.

Prado (2010) verificou que, na prática, os professores paranaenses não utilizam plenamente o Livro Didático Público. Esse Livro foi distribuído aos alunos do ensino médio da rede estadual a partir do ano de 2007. Esta organização é mais bem explicitada por Schlesener (2008):

O projeto editorial da Secretaria de Educação do Estado do Paraná nasceu com a proposição e a construção dos "Folhas", que se constituíram nos primeiros escritos elaborados por professores do Ensino Médio, no contexto de uma proposta mais ampla de formação continuada de professores e de recuperação da qualidade de ensino nas escolas públicas. O nome "Folhas" inicialmente se apresentou no imaginário como "palavras ao vento", isto é, fragmentos de reflexões que, aos poucos, tomavam forma num pensamento organizado e coerente sobre um determinado assunto (p. 34)

Constatou-se que eram poucos os professores a utilizá-lo e, quando o faziam, era apenas para ilustrar as aulas. Sua função era somente a de apresentar as ilustrações, mapas e imagens diversas. Simplesmente algumas imagens e determinados trechos dos documentos foram considerados relevantes. Considera-se que esse Livro público paranaense com o passar dos tempos poderá fazer parte, a cada dia, da prática pedagógica dos professores, exatamente por ser uma proposta metodológica inovadora. 
Atualmente, todos os volumes produzidos para os anos do Ensino Médio podem ser acessados na página eletrônica da Secretaria da Educação do Estado do Paraná, na página denominada Portal da Educação: Dia a Dia da Educação, e podem ser baixados em PDF no formato de livro digital. Os livros didáticos digitais disponíveis neste portal contemplam as disciplinas do Ensino Médio de Matemática, Química, Sociologia, Língua estrangeira Espanhol e Inglês - é um volume único para as duas disciplinas -, História, Geografia, Física, Educação Física, Filosofia, Biologia e Arte (Paraná, 2015).

\section{As Grandes Editoras e seus Livros Didáticos Impressos e Digitais}

A primeira editora de grande porte do Brasil foi a Francisco Alves. A princípio esse senhor era um comerciante de livros que percebeu a expansão do mercado de leitores e, em 1897, passou a "investir decididamente na literatura didática", como pontuou Bittencourt (2008, p. 67). Nos anos 40 a Companhia Editora Nacional já dominava o mercado de livros didáticos no país, como descreveu Cassiano (2014). Em 1943 foi criada a Editora do Brasil por antigos funcionários da Companhia Editora Nacional. Nessa mesma época a Editora Saraiva já publicava alguns livros didáticos. A FTD, sigla para Frère Théophane Durand, existia desde 1883, com a primeira publicação no Brasil em 1902. Os livros da Editora FTD usados no Brasil eram impressos na França até 1930, quando, nessa época, a editora passou a publicar seus livros em São Paulo, mas ainda não faziam a sua distribuição. A Editora FTD somente se tornou editora em 1963. A Editora Ática foi fundada em 1965 para publicar apostilas, que, com o tempo, tornaram-se livros didáticos.

Na maioria dos casos as editoras de livros didáticos nasceram para sanar os problemas que os professores encontravam no seu cotidiano. A princípio, no século 19, os livros eram apenas traduzidos, e, em seguida passaram a ser escritos por professores dos mais diversos níveis de ensino. No século 20, alguns desses professores-autores de livros didáticos tornaram-se proprietários de editoras. A cada nova editora criada tínhamos um livro ícone - normalmente escrito por seu 
proprietário -, que servia de marco para a publicação de outros volumes. Alguns livros foram por anos publicados pela mesma editora, com o mesmo autor, e chegavam a ser conhecidos pelos leitores pelo sobrenome ou nome do autor.

As inovações na apresentação dos conteúdos, porém, também eram relevantes. A Editora Ática, quando de sua fundação, instituiu "a existência de três livros em um só: o do professor, o caderno de exercícios consumível e o livro do aluno, todos mantendo a mesma diagramação", como apresentou Cassiano (2014, p. 159).

Nos anos iniciais do século 21 as editoras que predominavam no mercado nacional de livros didáticos eram: Grupo Saraiva, composto pelas Editoras Saraiva, Atual e Formato; Grupo Abril, formado com as Editoras Ática e Scipione; Grupo Santillana, com as Editoras Moderna, Salamandra, Objetiva e Richmon Publishing; Grupo Instituto Brasileiro de Edições Pedagógicas/Companhia Editora Nacional; Editora FTD, com as Editoras FTD e Quinteto; e, por fim, o Grupo Positivo, com a Editora Nova Didática, segundo dados descritos por Cassiano (2014). O quadro seguinte apresenta a movimentação das editoras de livros didáticos no Brasil a partir da segunda metade do século 20 .

Quadro 2 - Editoras de Livros Didáticos no Brasil

\begin{tabular}{|l|l|}
\hline Nomes & Ano de transição \\
\hline Companhia Editora Nacional & 1973 foi estatizada \\
\hline Companhia Editora Nacional & $\begin{array}{l}1980 \text { vendida para o Instituto Brasileiro de Edições } \\
\text { Pedagógicas (Ibep) }\end{array}$ \\
\hline Editora Atual & Fundada em 1973 \\
\hline Editora Atual & Vendida em 1998 para a Editora Saraiva \\
\hline Editora Moderna & Fundada em 1968 \\
\hline Editora Moderna & Comprada em 2001 pelo Grupo Santillana \\
\hline Editora Ática & Fundada em 1965 \\
\hline Editora Ática & Comprou em 1983 a Editora Scipione \\
\hline Editoras Ática e Scipione & Vendida em 1999 para os Grupos Abril e Havas \\
\hline Editora FTD & Criada em 1963 \\
\hline Editora FTD & Comprou em 1997 a Editora Quinteto \\
\hline
\end{tabular}

Fonte: Cassiano, 2014. 
As editoras foram se organizando e unindo-se umas às outras no sentido de ganharem maior expressão no mercado. Outra questão a ser levada em conta é a dos equívocos que ainda aparecem nos livros didáticos impressos. $\mathrm{Na}$ maioria das vezes, os conteúdos, imagens e ilustrações são revisados, mas com o aligeiramento nas produções, em razão dos prazos de entrega, ainda são várias as falhas encontradas. Pensando nas dificuldades de revisão recorrentes e nos curtos prazos de entrega para a distribuição, as editoras passaram a diversificar suas produções.

Os livros digitais, dessa maneira, surgirão como uma nova possibilidade para o mercado editorial. Nesse caso, por exemplo, o problema da distribuição não existe, os livros são baixados a qualquer momento e acessados imediatamente. As revisões nos conteúdos podem ser feitas sempre que forem detectados problemas, sem a necessidade de se esperar a próxima tiragem. Não ocorrem mais problemas com a entrega ou com a distribuição dos volumes para as escolas. Chartier (1998) comentou essa nova possibilidade do livro eletrônico:

\footnotetext{
Pode-se juntar aqui a reflexão sobre a edição e a distribuição, já que, no mundo do texto eletrônico, tudo isso é uma coisa só. Um produtor de texto pode ser imediatamente o editor, no duplo sentido daquele que dá forma definitiva ao texto e daquele que o difunde diante de um público de leitores: graças à rede eletrônica, esta difusão é imediata (Chartier, 1998, p. 16).
}

Apesar das editoras de livros didáticos nacionais já contarem com sites e livros digitalizados, essa modalidade de livro ainda não faz parte plenamente do cotidiano das salas de aula. Em algumas escolas privadas de grande porte da cidade de Curitiba são usados livros didáticos digitais apenas em algumas disciplinas específicas. A maioria dos professores conhece o formato dos livros digitais, mas não faz uso desta inovação em sala de aula. Segundo Kellner e Share (2008, p. 703), “as novas tecnologias da comunicação são ferramentas poderosas que podem libertar ou dominar, manipular ou esclarecer, e é vital que os educadores ensinem seus alunos a usarem e analisarem criticamente esses tipos de mídia". 
Os livros digitais são, em sua maioria, até o momento, apresentados no formato de ePub, também conhecido como livro eletrônico ou digital. São os mais difundidos por se adaptarem a telas diferentes e poderem ser lidos em tablets, e-readers, computadores ou smartphones. Esses livros normalmente estão disponíveis em PDF. Neste caso, os conteúdos do volume são digitalizados, exatamente como surgem no livro impresso. Na verdade, esse é um livro que foi preparado para ser comercializado em meio digital, de modo que seus conteúdos, imagens e atividades apareçam de legíveis quando lido no formato digital. Existe, ainda, a possibilidade de o livro eletrônico estar disponível em um CD-ROM, e ser lido em um suporte diferente. Ribeiro (2011, p. 131) descreveu que "o livro, assim como os jornais e as revistas, foi sendo reprojetado e consagrou-se como objeto portátil, que pode ser lido em qualquer lugar, mesmo nas ruas da cidade, em qualquer praça ou sala de espera".

Quanto aos suportes para leituras dos livros digitais podem-se listar vários deles a disposição do leitor. Caso o livro esteja em um CD-ROM ele poderá ser lido em qualquer equipamento que faça a leitura de um CD. Os livros digitais vendidos pelas editoras on-line podem ser baixados em diversos suportes diferentes. Caso o livro tenha sido elaborado em PDF, basta apenas instalar o programa para o funcionamento desse tipo de arquivo. Existem ainda equipamentos que são leitores específicos para livros digitais, que são vendidos nas livrarias e grandes magazines. Com o acesso e o avanço dos meios tecnológicos, entretanto, os livros digitais podem ser baixados e lidos em suportes distintos.

Com o passar do tempo e o desenvolvimento dos recursos, os suportes e as ferramentas para escrever e ler mudam. A prática do leitor fornece subsídios para que os produtores de material escrito e/ou de dispositivos para leitura possam repensar, reprojetar e reinventar materiais e recursos, de acordo com a demanda constante do leitor, que busca conforto, eficiência, eficácia, portabilidade e compreensibilidade. E o leitor vai se conformando ao objeto de ler, num ciclo retroalimentado e retroalimentador (Ribeiro, 2011, p. 126).

Sendo assim, acredita-se que a tendência seja a da difusão dos leitores digitais e que a escola se aproprie a cada dia destas inovações. As grandes editoras de livros didáticos impressos passaram a publicar seus livros em formato digital. 
O problema com o qual nos deparamos, até o momento, no entanto, é que os livros didáticos digitais são apenas reproduções eletrônicas dos livros impressos. A maioria dos volumes, analisada até a ocasião, somente apresenta as páginas dos volumes impressos em formato PDF. Talvez, a partir do ano de 2016, possamos encontrar uma maior variedade destes volumes em formato digital, em virtude da iniciativa do governo federal brasileiro em distribuir às escolas públicas da Educação Básica livros em formato digital.

Foi aberto pelo Ministério da Educação o edital de convocação 01/2013 visando à "Inscrição e Avaliação de obras didáticas para o programa nacional do livro didático do ano de 2015". Neste referido edital existem duas possibilidades para a apresentação dos livros didáticos digitais: podem ser introduzidos conjuntamente como obras impressas e livros em formato PDF, ou como livros digitais que trazem os conteúdos dos livros impressos e tenham correspondentes integrados a objetos educacionais digitais. Neste segundo modelo, o edital 01/2013 ainda traz as definições dos objetos educacionais: “[...] entende-se por objetos educacionais vídeos, imagens, áudios, textos, gráficos, tabelas, tutoriais, aplicações, mapas, jogos educacionais, animações, infográficos, páginas web e outros elementos". Esses objetos educacionais digitais deverão "ser acessados tanto pelo índice de referência como também pelos ícones nas páginas onde são referidos", e nos livros impressos deverão existir “[...] ainda que iconográfica, uma identificação visual dos objetos educacionais digitais que estão disponíveis nos livros digitais correspondentes". A partir deste edital pode-se supor que os livros didáticos digitais surjam com um formato mais interativo e tenham uma maior difusão, na medida em que essas disposições sejam colocadas em prática, nas escolas públicas e, consequentemente, nas privadas.

Neste ponto, todavia, deparamo-nos com outro obstáculo: a disponibilidade da ferramenta de leitura desses livros didáticos digitais. $\mathrm{O}$ edital e os programas de incentivo à difusão dos livros didáticos digitais da federação são relevantes e colocam o país diante da inovação tecnológica, mas os profissionais das escolas públicas de educação básica serão capacitados para acessar e utilizar essa nova ferramenta? Esta pode ser uma nova pesquisa, mas detenhamo-nos nos professores entrevistados que lecionam em escolas privadas. 


\section{Livros Digitais nas Escolas Privadas}

Esta pesquisa foi desenvolvida com profissionais que lecionam em quatro das grandes escolas privadas existentes na cidade de Curitiba, capital do Estado do Paraná. Dessas escolas, três delas são de caráter confessional e apenas uma é laica. Essa informação é relevante no sentido de demonstrar ao leitor que a manutenção das práticas pedagógicas não decorre apenas dos professores, mas, principalmente, da mantenedora da instituição de ensino em que esses trabalham. Nas escolas confessionais o uso dos livros didáticos digitais é elogiado pelos professores, mas não existe sua utilização concreta. Na escola laica são sados livros e outros materiais acessíveis aos professores e alunos de todas as faixas etárias. Neste caso, os professores recebem treinamento para a manipulação dos novos dispositivos acessíveis.

Os sujeitos foram convidados a participar da pesquisa, principalmente os professores com formação acadêmica em áreas específicas. Responderam esta pesquisa professores licenciados em Física, Química, Língua Portuguesa, Biologia, História e Filosofia. Todos os professores apresentam uma formação acadêmica mais aprofundada: $40 \%$ dos entrevistados tem título de mestre, $20 \%$ são doutores e $40 \%$ são especialistas. Levando-se em conta a formação acadêmica destes profissionais e as escolas nas quais trabalham, supõem-se que tenham total conhecimento dos dispositivos e das possibilidades e limites do uso dos livros didáticos digitais. O que a pesquisa revelou, no entanto, foi um breve desconhecimento sobre livros didáticos digitais, e ainda o ínfimo uso deste material didático.

Em contraponto a essa situação, temos os alunos atendidos por esses profissionais. São indivíduos dos quatro últimos anos do Ensino Fundamental e dos três anos do Ensino Médio, portanto entre 11 e 17 anos de idade, ou entre o $6^{\circ}$ Ano do Fundamental e o $3^{\circ}$ do Médio. Esse público está habituado ao manuseio de eletrônicos portáteis, exatamente em razão de sua condição social e econômica. O que se notou após a análise dos dados, porém, é a desinformação por parte dos professores sobre os conteúdos e a forma como esses são expressos nos livros didáticos digitais. Um dos professores, em seu depoimento sobre o livro didático digital, escreveu: “[...] imagino que existam links para artigos, 
textos referentes ao conteúdo trabalhado, que poderiam ser acessados do dispositivo, complementando a aula, indicações de vídeos, e outras possibilidades para ampliar os conteúdos das aulas" (Professor Física 1). Esse professor sabe da existência de livros didáticos digitais, mas nunca trabalhou com nenhum deles, nem ao menos teve a curiosidade de saber como são formatados, porque assim saberia que a maioria dos livros existentes no mercado editorial são apenas reproduções em formato PDF dos volumes impressos, sem a mínima interatividade.

Em outra entrevista, o professor escreveu que faz uso do livro didático digital, "[...] ele é disponibilizado na internet, para uso de todos os interessados" (Professor História 1). Nesta situação, o livro é utilizado apenas para resolução de exercícios, o formato da aula permanece a mesma, os conteúdos são expostos em sala pelo professor e para a fixação da aprendizagem são realizados apenas exercícios, com os livros digitais. O referido professor escreveu: “[...] são realizados com os alunos os exercícios propostos de forma coletiva, a fim de sanar dúvidas referentes aos conteúdos e mostrar outros caminhos para se chegar às respostas" (Professor História 1). Esse relato demonstra que o livro digital não é explorado, exatamente por esta possiblidade ainda não existir, uma vez que o livro se apresenta em formato PDF.

Apesar destes equívocos transitórios com a utilização em sala de aula dos livros didáticos digitais, todos os professores entrevistados concordam com a inovação tecnológica nos materiais escolares. Um deles defende a ideia de que é necessário também difundir o conhecimento tecnológico para professor e alunos, antes de se inserir na prática pedagógica essa tecnologia com livros digitais. $\mathrm{O}$ professor escreveu: “[...] temos de ter alfabetização tecnológica, produção do conhecimento. A questão é que temos de ter recursos tecnológicos em benefício da educação e para fins pedagógicos" (Professor Química 2). Já outro professor aponta a necessidade de se criarem políticas públicas que viabilizem e sustentem tais propostas tecnológicas na área da educação para todos os professores, independentemente se lecionam em escolas da rede privada ou pública.

[...] o que é importante destacar é a necessidade de se pensar uma política pública de qualificação para os professores. Se os professores tiverem tempo para estudar, buscar novos materiais, etc..., as aulas e os resultados 
da aprendizagem serão, certamente melhores, com ou sem livros didáticos digitais. As novas tecnologias não são a panaceia social pelo simples fato de existirem (Professor Filosofia 1).

A partir do momento em que os livros didáticos digitais passem a assumir um caráter plenamente interativo, todavia, esses profissionais poderão ter acesso aos conteúdos estabelecidos por disciplina e ainda fazerem uso de objetos educacionais digitais - como foram denominados em edital do Ministério da Educação - que contribuirão para o ensino destes conteúdos. Um dos professores entrevistados escreveu sobre as possibilidades do uso de livros didáticos digitais interativos ou compostos por objetos educacionais digitais.

[...] essa nova tecnologia não somente pode resultar em conhecimento teórico de um determinado assunto, mas também pode fornecer um embasamento visual para a prática dos mais variados temas que sejam do interesse de um pesquisador. O livro digital se apresenta como um imenso banco de dados que extrapola as paredes das bibliotecas tradicionais, contendo, em contínua circulação e atualização e um espaço totalmente novo para vários tipos de buscas de conhecimento, possibilitando incursões a diferentes tipos de fontes, muitas vezes restritos quando se fala no livro impresso. Na situação geopolítica contemporânea, o aluno pesquisador tem ao seu dispor dados fundamentais para suas pesquisas. Desta forma, o aluno pode integrar procedimentos de sua pesquisa por meio on-line compartilhando informações (Professor História 1).

As análises e opiniões dos professores entrevistados demonstram que os mesmos estão interessados nas inovações e possibilidades de trabalho com o livro didático digital, mas, na realidade, não sabem efetivamente quais são e como são os formatos desses livros que atualmente estão acessíveis no mercado para aquisição.

\section{Considerações Finais}

A inclusão das novas tecnologias nas instituições de ensino da Educação Básica é inevitável. O acesso aos novos meios tecnológicos se expande paulatinamente dentro das salas de aula. A comunidade escolar, apesar da 
resistência da prática pedagógica por parte de alguns profissionais e algumas instituições, terá de se inteirar sobre as inovações tecnológicas voltadas à educação. A inclusão digital visa a uma melhoria na metodologia de ensino, tendo como base de análise os livros didáticos digitais. Bastará apenas que esses livros - neste novo formato - assumam um caráter mais interativo em seu intercâmbio com professores e alunos. Apesar de exaustiva pesquisa sobre essa temática em outros países, não foi possível identificar essa mesma discussão. A relevância desta pesquisa está nas peculiaridades brasileiras, e este estudo foi o único a abordar esse assunto no IV Congreso de la Internacional del Conocimiento: ciencias, tecnologias y culturas, mirando al futuro de America Latina y Caribe, ocorrido no ano de 2015 na cidade de Santiago no Chile. Em países do hemisfério norte, como Espanha, França, Canadá ou Estados Unidos, a realidade no uso dos livros didáticos digitais é diametralmente diversa da realidade brasileira.

Até o momento, conforme os dados das entrevistas efetuadas com os professores de algumas das escolas privadas da cidade de Curitiba, os profissionais da educação demonstraram certa cautela com o uso do livro didático digital, mesmo que o formato deste seja o mesmo do livro impresso. Talvez, com o passar do tempo, o uso específico deste formato de livro, ganhe espaço nas salas de aula, quando o suporte para a leitura do livro se tornar mais acessível e, consequentemente, reconhecido pela comunidade escolar; até então, muitos dos suportes que possibilitariam a leitura de livros didáticos digitais são, em alguns casos, impedidos de circularem livremente nas salas de aula.

Independentemente de qual seja o acesso aos meios digitais, as inovações pedagógicas devem ocorrer paulatinamente. Os professores poderiam alterar sua prática de trabalho com livros didáticos impressos para livros didáticos digitais quando considerarem que têm o domínio desta ferramenta. O momento em que nos encontramos ainda é um período de transição, de conhecimento de uma nova opção de trabalhar os conteúdos em sala de aula. O livro didático digital não atinge a grande população escolar. Talvez até o final do próximo decênio professores e alunos possam ter acesso pleno a esse formato para a apresentação dos conteúdos. 
Como temos ciência, as alterações nas práticas pedagógicas são extremamente paulatinas, de modo a crermos que, com o passar dos tempos, novos resultados serão conquistados e, consequentemente, novas pesquisas divulgadas a esse respeito.

\section{Referências}

BATISTA, Antônio. Um objeto variável e instável: textos, impressos e livros didáticos. In: ABREU, Márcia (Org.). Leitura, história e história da leitura. Campinas, SP: Mercado das Letras; Associação de Leitura do Brasil; Fapesp, 2002. p. 529-576.

BITTENCOURT, Circe M. Fernandes. Livro didático e saber escolar: 1810-1910. Belo Horizonte, MG: Autêntica, 2008.

BRASIL. Programa Nacional do Livro Didático. Brasília: Ministério da Educação, 2014. . Edital de Convocação 01/2013: edital para o processo de inscrição e avaliação de obras didáticas para o Programa Nacional do Livro Didático, para o ano de 2015. Fundo Nacional de Desenvolvimento da Educação. Secretaria da Educação Básica. Brasília: Ministério da Educação, 2013.

CASSIANO, Célia C. de Figueiredo. Mercado do livro didático no Brasil no século XXI:a entrada do capital espanhol na educação nacional. São Paulo: Editora da Unesp, 2014.

CHARTIER, Roger. A aventura do livro: do leitor ao navegador, conversações com Jean Lebrun. Trad. Reginaldo C. C. Moraes, $1^{a}$ reimpr. São Paulo: Imesp: Editora da Unesp, 1998.

HÖFLING, Heloisa de Matos. Notas para discussão quanto à implementação de programas de governo: Em foco o Programa Nacional do Livro Didático. Campinas/SP, Revista Educação \& Sociedade, ano XXI, n. 70, p. 159-170, abr. 2000.

KELLNER, Douglas; SHARE, Jeff. Educação para a leitura crítica da mídia: democracia radical e a reconstrução da educação. Campinas, SP, Revista Educação \& Sociedade, v. 29, n. 104, p. 687-715, out. 2008.

MIMESSE, Eliane. A educação e os imigrantes italianos: da escola de primeiras letras ao grupo escolar. 2. ed. São Paulo: Iglu, 2010.

MUNAKATA, Kazumi. Livro didático: produção e leituras. In: ABREU, Márcia (Org.) Leitura, história e história da leitura. Campinas, SP: Mercado das Letras: Associação de Leitura do Brasil; São Paulo: Fapesp, 2002. p. 577-594. 
PARANÁ. Recursos didáticos: livros didáticos. Secretaria de Educação do Estado do Paraná. Curitiba: Portal Dia a Dia da Educação, 2015. Disponível em: <http://www. educadores.diaadia.pr.gov.br/modules/conteudo/conteudo.php?conteudo=6>. Acesso em: 16 ago. 2015.

PRADO, Eliane M. Sugestões metodológicas dos currículos oficiais para o ensino de História. Campina Grande, PB, Revista de Ciências Humanas e Artes - Ariús, v.16, n.1/2, p. 99-107, 2010.

A disciplina história nos anos da ditadura militar. Jundiaí, SP: Paco Editorial, 2014.

PROFESSORES. Respostas dos questionários aplicados aos professores das disciplinas da educação básica de física, química, língua portuguesa, filosofia, biologia e história. Curitiba, 2015.

RIBEIRO, Ana. Ler na tela: letramento e novos suportes de leitura e escrita. In: COSCARELLI, Carla; RIBEIRO, Ana (Org.). Letramento digital: aspectos sociais e possibilidades pedagógicas. 3. ed. Belo Horizonte: Centro de Alfabetização, Leitura e Escrita da UFMG. Belo Horizonte: Autêntica, 2011. p. 25-49.

SCHLESENER, Anita. Políticas públicas do livro didático: a experiência do Paraná. Cadernos de Pesquisa: pensamento educacional. Curitiba, v.3, n. 6, p.33-45, jul./dez. 2008.

Recebido em: 16/9/2015

Aceito em: 29/7/2016 